\title{
DETERMINAÇÃO DA CONCENTRAÇÃO MÍNIMA INIBITÓRIA DE SULFATO DE CEFQUINOMA FRENTE A AGENTES BACTERIANOS ASSOCIADOS A CASOS DE MASTITE BOVINA
}

\author{
HARTWIG, Carla de Andrade ${ }^{1}$, \\ BARROS, Alice Calixto de ${ }^{2}$, \\ VIANNA, Paula de Souza Machado ${ }^{3}$, \\ LADEIRA, Silvia Regina Leal ${ }^{4}$,
}

${ }^{1}$ Doutoranda do Programa de Pós-Graduação em Química, UFPEL; ${ }^{2}$ Acadêmica de Medicina Veterinária, URCAMP; ${ }^{3}$ Médica Veterinária Autônoma; ${ }^{4}$ Médica Veterinária do Laboratório Regional de Diagnóstico, FVet/UFPEL.

\section{RESUMO}

\begin{abstract}
A atividade in vitro de sulfato de cefquinoma, um antibiótico da classe das cefalosporinas, foi avaliada frente aos agentes bacterianos: Staphylococcus sp. (coagulase negativo), Staphylococcus aureus, Streptococcus sp., Streptococcus uberis, Streptococcus dysgalactiae, Streptococcus pyogenes, Trueperella pyogenes, Nocardia sp., Corynebacterium sp. e Bacillus cereus, isolados de amostras de leite coletadas de vacas que apresentavam mastite clínica ou subclínica. A Concentração Mínima Inibitória (CMI) para cada uma das bactérias testadas foi definida a partir da avaliação de diferentes concentrações de sulfato de cefquinoma, em um intervalo de 0,014 a 115,781 $\mu \mathrm{g} \cdot \mathrm{ml}^{-1}$. As $\mathrm{CMI}$ obtidas para a maioria dos agentes bacterianos foi inferior a $2 \mu \mathrm{g} . \mathrm{ml}^{-1}$, com exceção da Nocardia sp. que necessitou de concentrações maiores de antibiótico, e do Staphylococcus aureus que apresentou resistência a todas as concentrações de sulfato de cefquinoma avaliadas.
\end{abstract}

Palavras-chave: Sulfato de cefquinoma. Concentração mínima inibitória. Agentes bacterianos. Mastite bovina. 


\section{INTRODUÇÃO}

Um dos grupos mais importantes de antibióticos, tanto sob o ponto de vista histórico como médico, corresponde aos $\beta$-lactâmicos. Este grupo inclui as penicilinas, cefalosporinas e cefaminas de importância médica. Em conjunto, as penicilinas e cefalosporinas correspondem a mais da metade de todos os antibióticos produzidos e utilizados no mundo (MADIGAN et al., 2010).

A cefquinoma é um antibiótico da classe das cefalosporinas, com ação similar a de outros antibióticos $\beta$-lactâmicos, inibindo a síntese da parede bacteriana e provocando a morte da célula. As cefalosporinas são classificadas, dependendo do seu espectro de ação, em antibióticos de primeira, segunda, terceira e quarta gerações, sendo que a cefquinoma se enquadra como pertencente a esta última classe. Em comparação com as chamadas cefalosporinas de terceira geração, os agentes pertencentes à quarta geração, mostram uma maior atividade contra bactérias Gram-negativas, e não são afetados pelas cefalosporinases mediadas por cromossomos do tipo AMP-C, ou pela $\beta$-lactamase mediada por plasmídeos de alguns bacilos Gram-negativos (PAPICH, 2012; THOMAS et al., 2006).

O uso de cefquinoma tem revelado alta atividade in vitro contra um largo espectro de agentes patogênicos da espécie bovina, mais precisamente contra agentes causadores de mastite, cujo tratamento com este antibiótico tem sido amplamente relatado na literatura (GRUET et al., 2001; ROBERSON, 2012; SUHREN; KNAPPSTEIN, 2003; SWINKELS et al., 2013). A partir disso, estudos de Concentração Mínima Inibitória (CMI) deste antibiótico têm sido realizados por alguns autores, com o intuito de conhecer a susceptibilidade de agentes bacterianos variados frente à cefquinoma (CHIN et al., 1992; GUÉRIN-FAUBLÉE et al., 2002; THOMAS et al., 2006; ZONCA et al., 2011).

Por CMI, entende-se a menor quantidade de um agente antimicrobiano necessária para inibir o crescimento de um micro-organismo teste. Os ensaios de avaliação da CMI de um antibiótico são importantes para a obtenção de informações que auxiliem na indicação terapêutica do medicamento. Os mais conhecidos ensaios de determinação de CMI incluem método de difusão em ágar, método de macrodiluição, e método de microdiluição, os quais 
constituem procedimentos padronizados, capazes de fornecer resultados quantitativos (BRITO et al., 2001; NCCLS, 2003; OLIVEIRA et al., 2009; OSTROSKY et al., 2008).

Assim, considerando-se que a terapia antimicrobiana continua a ser um componente importante nos programas de controle da mastite bovina, doença mais frequente na pecuária leiteira (BRITO et al., 2001; GUÉRIN-FAUBLÉE et al., 2002), e que a seleção do antimicrobiano apropriado em concentração adequada é essencial, tanto do ponto de vista da saúde do animal, quanto da produtividade da glândula mamária (BRITO et al., 2001), neste trabalho objetivou-se isolar e identificar agentes bacterianos a partir de casos de mastite bovina e, posteriormente, determinar a CMI de sulfato de cefquinoma frente aos diferentes agentes isolados.

\section{MATERIAL E MÉTODOS}

\section{Isolamento e identificação das bactérias}

Foram avaliadas 72 amostras de leite, pertencentes a rebanhos leiteiros localizados no sul do estado do Rio Grande do Sul, nos municípios de Rio Grande, São Lourenço do Sul, Santa Vitória do Palmar e Cerrito. Essas amostras foram coletas de vacas que apresentavam mastite clínica ou subclínica, baseando-se em testes de verificação do conteúdo leucocitário do leite, como a contagem de células somáticas (CCS).

O isolamento bacteriano foi feito a partir de leite coletado antes da ordenha, após cuidadosa antissepsia dos tetos com álcool a $70 \% \mathrm{v} / \mathrm{v}$. Os jatos de leite foram coletados em frascos estéreis, colocados em caixas isotérmicas com gelo e encaminhados ao laboratório para processamento. As amostras foram semeadas em placas de ágar MacConkey e ágar sangue contendo $5 \%$ de sangue ovino desfibrinado, sendo posteriormente incubadas por 24 a 72 horas, em temperatura de $37^{\circ} \mathrm{C}$. Após, as colônias isoladas foram classificadas de acordo com as características morfotintoriais e bioquímicas.

Os agentes isolados foram utilizados para a determinação da CMI de antibiótico bactericida injetável à base de sulfato de cefquinoma. 


\section{Preparo dos inóculos e determinação da CMI de sulfato de cefquinoma frente às bactérias isoladas}

Inicialmente foram preparados pré-inóculos das bactérias isoladas dos casos de mastite bovina, a partir de diluição das mesmas em solução salina $0,85 \% \mathrm{~m} / \mathrm{v}$, até a turbidez de uma solução padrão de McFarland 0,5.

A determinação da CMI de sulfato de cefquinoma frente aos agentes isolados foi realizada por meio de método de microdiluição em caldo, em três repetições, empregando microplacas de plástico estéreis contendo 96 poços distribuídos em 12 colunas, próprias para microdiluição, segundo adaptações das recomendações do NCCLS (2003), e do trabalho de Oliveira et al. (2009).

Neste procedimento, foram preparadas diluições seriadas do antibiótico à base de sulfato de cefquinoma, a partir da aplicação de $150 \mu \mathrm{l}$ de caldo Brain Heart Infusion broth (BHI) nos poços da 1a coluna, e da $3 \underline{a}$ até a última coluna da microplaca. Na $2 \underline{a}$ coluna foi preparado $300 \mu \mathrm{l}$ da concentração mais alta do antibiótico, a partir da qual foi iniciada uma diluição seriada do mesmo (fator $2 \mathrm{x}$ ) ao longo da microplaca, até a penúltima coluna utilizada. Para isto, metade do volume dos poços da $2 \underline{a}$ coluna $(150 \mu \mathrm{l})$ foi transferido mediante o uso de micropipeta para os poços da 3 a coluna, e assim sucessivamente. Realizou-se assim a diluição e homogeneização até a penúltima coluna utilizada, a qual, após homogeneização, teve metade de seu conteúdo $(150 \mu l)$ descartado, visto que a última coluna foi mantida sem antibiótico.

Assim, o intervalo de concentração de sulfato de cefquinoma na microplaca, a partir da $3 \underline{a}$ coluna, até a penúltima coluna, foi decrescente, de 115,781 a 0,014 $\mu \mathrm{g} \cdot \mathrm{ml}^{-1}$. Estas concentrações foram escolhidas a partir de valores de CMI de antibióticos à base de cefquinoma e outras substâncias, frente a bactérias diversas (BRITO et al., 2001; CHIN et al., 1992; GUÉRIN-FAUBLÉE et al., 2002; THOMAS et al., 2006).

A inoculação das bactérias nas colunas da microplaca se deu pela utilização de $10 \mu \mathrm{l}$ de suspensão bacteriana do pré-inóculo, em cada poço contendo caldo $\mathrm{BHI}$ com antibiótico diluído (da $3^{a}$ até a penúltima coluna, chamadas colunas de teste) ou apenas caldo $\mathrm{BHI}$ (última coluna, chamada coluna de controle positivo). Cabe destacar que cada linha da 
microplaca corresponde à inoculação de uma bactéria diferente, e que as suspensões dos pré-inóculos utilizadas foram diluídas em até 15 minutos após sua preparação, de maneira que, após a inoculação final na microplaca, cada poço da mesma contivesse aproximadamente $5 \times 10^{5}$ UFC.ml ${ }^{-1}$. Esta concentração foi definida levando-se em consideração o volume de caldo $\mathrm{BHI}$ presente em cada poço, previamente à aplicação do inóculo. A primeira coluna da microplaca foi mantida somente com caldo BHI (chamada coluna de controle negativo).

Após a inoculação, as microplacas foram incubadas a $37{ }^{\circ} \mathrm{C}$ por 24 horas, e, após este período, a CMI para cada bactéria avaliada foi definida a partir da identificação visual da menor concentração de antibiótico em que não foi verificada a ocorrência de turvação, o que representa um indício de crescimento bacteriano. Estes resultados foram confirmados por semeadura de alíquotas de $5 \mu \mathrm{l}$ das culturas presentes em cada um dos poços da microplaca em ágar sangue, as quais foram incubadas a $37{ }^{\circ} \mathrm{C}$ por 24 a 72 horas, a fim de verificar a presença ou ausência de bactérias em cada uma das concentrações de antibiótico avaliadas.

\section{RESULTADOS E DISCUSSÃO}

Dentre as amostras de leite analisadas, coletadas de vacas que apresentavam mastite clínica ou subclínica, verificou-se um percentual de ausência de crescimento bacteriano de $28 \%$. Por sua vez, o crescimento de poliflora foi verificado em $19 \%$ das amostras, enquanto que nos 53\% restantes, foi possível o isolamento de dez diferentes agentes bacterianos: Staphylococcus sp. (coagulase negativo), Staphylococcus aureus, Streptococcus sp., Streptococcus uberis, Streptococcus dysgalactiae, Streptococcus pyogenes, Trueperella pyogenes, Nocardia sp., Corynebacterium sp. e Bacillus cereus.

Cabe salientar que a predominância do gênero Streptococcus dentre os agentes isolados pode ser explicada pelo fato destes serem reconhecidamente os principais patógenos causadores de mastite, juntamente com o Staphylococcus aureus e coliformes (GUÉRINFAUBLÉE et al., 2002). 
A CMI de sulfato de cefquinoma para cada um dos agentes isolados foi determinada por meio de método de microdiluição em caldo, cujos resultados obtidos estão apresentados na Tabela 1. Cabe ressaltar que estes valores foram definidos a partir da menor concentração de antibiótico onde não foi verificado crescimento bacteriano, sendo que foi possível correlacionar a ocorrência de turvação do conteúdo dos poços da microplaca com a verificação de crescimento bacteriano em àgar sangue.

Tabela 1. Concentração mínima inibitória de sulfato de cefquinoma para diferentes agentes bacterianos provenientes de casos de mastite bovina, definida a partir de três repetições de teste de microdiluição em caldo.

\begin{tabular}{lc}
\hline Agentes bacterianos & $\mathrm{CMI}\left(\mu \mathrm{g} \cdot \mathrm{ml}^{-1}\right.$ ) \\
\hline Staphylococcus sp. (coagulase negativo) & 0,452 \\
Staphylococcus aureus & $\mathrm{nd}$ \\
Streptococcus sp. & 0,452 \\
Streptococcus uberis & 0,452 \\
Streptococcus dysgalactiae & 0,452 \\
Streptococcus pyogenes & 0,452 \\
Trueperella pyogenes & 0,452 \\
Nocardia sp. & 28,945 \\
Corynebacterium sp. & 0,452 \\
Bacillus cereus & 1,809 \\
\hline *nd não determinada nas concentrações avaliadas. &
\end{tabular}

Como pode-se observar na Tabela 1 , a CMI de sulfato de cefquinoma frente a maioria dos agentes bacterianos testados foi $0,452 \mu \mathrm{g} \cdot \mathrm{ml}^{-1}$, com exceção do Bacillus cereus, cuja CMI foi próxima de $2 \mu \mathrm{g} \cdot \mathrm{ml}^{-1}$, e da Nocardia sp. que mostrou-se mais resistente ao antibiótico, necessitando de concentração igual a $28,945 \mu \mathrm{g} \cdot \mathrm{ml}^{-1}$ para a inibição de seu crescimento, resultando assim no maior valor de CMI determinado neste trabalho.

Além disso, o desenvolvimento do experimento permitiu observar que o Staphylococcus aureus mostrou-se resistente a todas as concentrações de antibiótico testadas, diferentemente de trabalhos da literatura onde foram determinadas $\mathrm{CMI}$ de sulfato de 
cefquinoma entre 0,5 e $8 \mu \mathrm{g} \cdot \mathrm{ml}^{-1}$ para este agente (CHIN et al., 1992; THOMAS et al., 2006; ZONCA et al., 2011).

Salienta-se também que, dentre os agentes isolados das amostras de leite, o Corynebacterium sp. e a Trueperella pyogenes apresentaram inibição de crescimento bacteriano a partir da concentração mínima de $0,452 \mu \mathrm{g} \cdot \mathrm{ml}^{-1}$ de sulfato de cefquinoma. $\mathrm{O}$ mesmo comportamento foi verificado para todos os agentes do gênero Streptococcus avaliados neste trabalho. Estes valores de CMI corroboram com dados do trabalho de Zonca et al. (2011), onde são relatadas CMI de sulfato de cefquinoma de até $0,5 \mu \mathrm{g} \cdot \mathrm{ml}^{-1}$ para Streptococcus sp., embora para as espécies dysgalactiae e uberis, os valores de CMI relatados por estes autores não ultrapassam $0,25 \mu \mathrm{g} \cdot \mathrm{ml}^{-1}$.

Por sua vez, no trabalho de Guérin-Faublée et al. (2002), é relatada a necessidade de uma concentração mínina de $1 \mu \mathrm{g} \cdot \mathrm{ml}^{-1}$ de sulfato de cefquinoma para a inibição do crescimento bacteriano de Streptococcus uberis, o que representa um valor superior ao obtido no presente experimento.

Cabe ressaltar ainda, com relação ao Streptococcus uberis, que no trabalho de GuérinFaublée et al. (2002) este agente reconhecido como o patógeno mais comumente isolado em casos de mastite clínica e principal causa de reinfecção, é também apontado como portador de características de maior resistência a antibióticos do que outras espécies do mesmo gênero, como por exemplo, o Streptococcus dysgalactiae. Entretanto, este comportamento não foi verificado no presente trabalho, quando a CMI determinada para ambas as espécies foi a mesma.

Discrepâncias com dados da literatura também foram observadas para os agentes Streptococcus pyogenes e Streptococcus dysgalactiae quando os valores para a CMI de sulfato de cefquinoma obtidos mostraram-se superiores aos relatados por Chin et al. (1992) e Guérin-Faublée et al. (2002), respectivamente.

Com relação ao agente bacteriano Staphylococcus sp. (coagulase negativo), verificou-se neste trabalho um valor de CMI bastante inferior ao observado por Chin et al. (1992), quando são reportados valores de até $16 \mu \mathrm{g} \cdot \mathrm{ml}^{-1}$. 
Entretanto, cabe ressaltar que esta inconstância da CMI para um mesmo agente microbiano tem sido relatada na literatura, em função da possibilidade de a mesma ser afetada pela natureza do micro-organismo teste utilizado, composição do meio de cultura, tempo e condições de incubação. Desta forma, nem sempre é possível a comparação direta entre resultados obtidos em estudos de avaliação de $\mathrm{CMI}$, com resultados encontrados na literatura, para um mesmo antibiótico (OLIVEIRA et al., 2009).

\section{CONCLUSÃO}

Com relação aos agentes bacterianos isolados de casos de mastite bovina neste trabalho, 40\% foram identificados como pertencentes ao gênero Streptococcus, o que era já esperado tendo em vista a sua predominância nos isolados deste tipo de doença.

A CMI de sulfato de cefquinoma, avaliada frente aos diferentes agentes microbianos isolados, permitiu o conhecimento de uma concentração mínima satisfatória de dosagem do antibiótico para nove dos dez agentes isolados, visto que o Staphylococcus aureus mostrouse resistente a todas as concentrações de antibiótico testadas.

Para os demais agentes bacterianos avaliados, verificou-se em sua maioria, uma CMI de sulfato de cefquinoma de 0,452 $\mu \mathrm{g} \cdot \mathrm{ml}^{-1}$, com exceção de Bacillus cereus e Nocardia sp. que apresentaram CMIs diferenciadas.

A parcela de micro-organismos que não teve sua CMI determinada neste estudo deve motivar a continuidade do mesmo, empregando concentrações mais elevadas de sulfato de cefquinoma, com vistas à inibição do crescimento bacteriano, conforme verificada para os demais agentes avaliados.

Ressalta-se ainda, que a indicação terapêutica de sulfato de cefquinoma deve levar em consideração os valores obtidos para CMI deste antibiótico, neste e em outros trabalhos, a fim de que o tratamento proporcione níveis de antimicrobiano satisfatórios no local da infecção. 


\title{
DETERMINATION OF MINIMUM INHIBITORY CONCENTRATION OF CEFQUINOME SULFATE AGAINST BACTERIAL AGENTS ASSOCIATED WITH CASES OF BOVINE MASTITIS
}

\begin{abstract}
$\mathrm{T}$ he in vitro activity of cefquinome sulfate, an antibiotic of the cephalosporin class, was evaluated against ten bacterial agents: Staphylococcus sp. (coagulase negative), Staphylococcus aureus, Streptococcus sp., Streptococcus uberis, Streptococcus dysgalactiae, Streptococcus pyogenes, Trueperella pyogenes, Nocardia sp., Corynebacterium sp. and Bacillus cereus, isolated from milk samples collected from cows with clinical or subclinical mastitis. The minimum inhibitory concentration (MIC) for each of the tested bacteria was defined based on the evaluation of different concentrations of cefquinome sulfate, that ranged from 0.014 to $115.781 \mu \mathrm{g} \cdot \mathrm{ml}^{-1}$. The MICs determined for most bacterial agents were less than $2 \mu \mathrm{g} \cdot \mathrm{ml}^{-1}$, except for Nocardia sp. that required higher concentrations of the antibiotic, and Staphylococcus aureus that was resistant to all concentrations of cefquinome sulphate evaluated.
\end{abstract}

Keywords: Cefquinome sulfate. Minimun inhibitory concentration. Bacterial agents. Bovine mastitis.

\section{DETERMINACIÓN DE LA CONCENTRACIÓN INHIBITORIA MÍNIMA DE SULFATO DE CEFQUINOMA CONTRA LOS AGENTES BACTERIANOS ASOCIADOS A LA MASTITIS BOVINA}

\section{RESUMEN}

a actividad in vitro de sulfato de cefquinoma, un antibiótico de la clase de las cefalosporinas, se evaluó contra diez agentes bacterianos: Staphylococcus sp. (coagulasa negativo), Staphylococcus aureus, Streptococcus sp., Streptococcus uberis, Streptococcus dysgalactiae, Streptococcus pyogenes, Trueperella pyogenes, Nocardia sp., Corynebacterium sp. y Bacillus cereus, aislados a partir de muestras de leche obtenidas de vacas con mastitis clínica o subclínica. La concentración inhibitoria mínima (CIM) para cada una de las bacterias probadas se definió a partir de la evaluación de diferentes concentraciones de sulfato de cefquinoma, en un rango de 0,014 a 115,781 $\mu \mathrm{g} \cdot \mathrm{ml}^{-1}$. Las CIM obtenidas para la mayoría de los agentes bacterianos fue de menos de $2 \mu \mathrm{g} \cdot \mathrm{ml}^{-1}$, con la excepción de Nocardia sp. que necesitó concentraciones más altas de antibióticos, y Staphylococcus aureus que era resistente a todas las concentraciones evaluadas de sulfato de cefquinoma.

Palabras clave: Sulfato de cefquinoma. Concentración inhibitoria mínima. Agentes bacterianos. Mastitis bovina. 


\section{REFERÊNCIAS}

BRITO, M. A. V. P.; BRITO, J. R. F.; SILVA, M. A. S.; CARMO, R. A. Concentração mínima inibitória de dez antimicrobianos para amostras de Staphylococcus aureus isoladas de infecção intramamária bovina. Arquivo Brasileiro de Medicina Veterinária e Zootecnia, v. 53, n. 5, p. 531-537, 2001.

CHIN, N-X.; GU, J-W.; FANG, W.; NEU, H. C. In vitro Activity of Cefquinome, a New Cephalosporin, Compared with Other Cephalosporin Antibiotics. Diagnostic Microbiology and Infectious Disease, v. 15, p. 331-337, 1992.

GRUET, P.; MAINCENT, P.; BERTHELOT, X.; KALTSATOS, V. Bovine mastitis and intramammary drug delivery: review and Perspectives. Advanced Drug Delivery Reviews, v. 50, p. 245-259, 2001.

GUÉRIN-FAUBLÉE, V.; TARDY, F.; BOUVERON, C.; CARRET, G. Antimicrobial susceptibility of Streptococcus species isolated from clinical mastitis in dairy cows. International Journal of Antimicrobial Agents, v. 19, p. 219-226, 2002.

MADIGAN, M. T.; MARTINKO, J. M.; DUNLAP, P. V.; CLARK, D. P. Microbiologia de Brock. 12a ed., São Paulo: Artmed, 2010. 795p.

NCCLS. National Committee for Clinical Laboratory Standards. Methods for Dilution Antimicrobial Susceptibility Tests for Bacteria That Grow Aerobically; Approved Standard-Sixth Edition. Waine: NCCLS, Document M7-A6, v. 23, n. 2, 2003. 54p.

OLIVEIRA, T. F.; FERREIRA, J. S.; BOA SORTE, P. M. F.; REIS, V. M.; BALDANI, J. I.; SCHWAB, S. Concentração Mínima Inibitória (CMI) de antibióticos para oito estirpes de bactérias diazotróficas da Coleção de Culturas da Embrapa Agrobiologia. Boletim de Pesquisa e Desenvolvimento, v. 49, Seropédica: Embrapa Agrobiologia, 2009, 16p.

OSTROSKY, E. A.; MIZUMOTO, M. K.; LIMA, M. E. L.; KANEKO, T. M.; ISHIKAWA, S. O.; FREITAS, B. R. Métodos para avaliação da atividade antimicrobiana e determinação da concentração mínima inibitória (CMI) de plantas medicinais. Brazilian Journal of Pharmacognosy, v. 18, n. 2, p. 301-307, 2008.

PAPICH, M. G. Manual Saunders de Terapia Veterinária. São Paulo: Elsevier, 2012. 880p.

ROBERSON J. R. Treatment of Clinical Mastitis, Veterinary Clinics of North America: Food Animal Practice, v. 28, p. 271-288, 2012.

SUHREN, G.; KNAPPSTEIN, K. Detection of cefquinome in milk by liquid chromatography and screening methods. Analytica Chimica Acta, v. 483, p. 363-372, 2003. 
SWINKELS, J. M.;. LAM, T. J. G. M; GREEN, M. J.; BRADLEY, A. J. Effect of extended cefquinome treatment on clinical persistence or recurrence of environmental clinical mastitis. The Veterinary Journal, v. 197, p. 682-687, 2013.

THOMAS, E.; THOMAS, V.; WILHELM, C. Antibacterial activity of cefquinome against equine bacterial pathogens. Veterinary Microbiology, v. 115, p. 140-147, 2006.

ZONCA, A.; GALLO, M.; LOCATELLI, C.; CARLI, S.; MORONI, P.; VILLA, R.; CAGNARDI, P. Cefquinome sulfate behavior after intramammary administration in healthy and infected cows. Journal of Dairy Science, v. 94, p. 3455-3461, 2011.

Autor para correspondência: Carla de Andrade Hartwig. Campus Universitário Capão do Leão, s/n, Faculdade de Veterinária. CEP: 96010-900. carlahartwig@yahoo.com.br 